\title{
Of All Antioxidants, Would One Finally Be Used Clinically For Atherosclerotic Disease?
}

\author{
Suko Adiarto
}

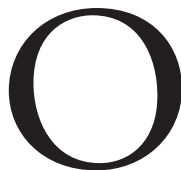

xidation of LDL by oxygen free radicals results in unregulated uptake of modified LDL by macrophages in arterial wall. This is considered a key initiating factor for development and progression of atherosclerotic process. It is then logical to hypothesize that antioxidants, which can directly scavenge free radicals, can be useful in preventing atherosclerotic process. Initial support for this hypothesis accumulated rapidly from numerous in-vitro studies.

The evidence was upgraded into the next level by studies involving animal models, in which various models of atherosclerotic diseases including high cholesterol-fed animals and genetically modified atherosclerotic mice (apo-E deficient mice) were shown to have increased parameters of oxidative stress in the arterial walls, including the up-regulation of inflammatory cytokines and adhesion molecules that preceded the development of atherosclerosis. Additionally, administration of antioxidants in these animal models resulted in the decrease of not only the inflammatory cytokines and adhesion molecules but also in the histological evidence of atherosclerosis size.

\section{Alamat Korespondensi:}

Suko Adiarto, MD, PhD. Departemen Kardiologi dan Kedokteran Vaskular FKUI, Pusat Jantung Nasional Harapan Kita, Jakarta. E-mail: sukoadiarto@gmail.com
The association was further strengthen by epidemiological studies in which population with low level of antioxidants is associated with a more prevalent atherosclerotic disease. In addition, population who traditionally consume foods and drinks containing antioxidants have significantly lower prevalence of atherosclerotic diseases.

Unfortunately, epidemiological study is as far as it can go. Ultimate evidence from interventional studies i.e. randomized placebo-controlled clinical trials almost uniformly yielded in disappointing results. Consequently, antioxidant supplement currently has no recommendation in daily practice, although intake from their primary food resources especially fruit and vegetables should still be encouraged.

The studies by Hendarto et.al in this edition of Indonesian Journal of Cardiology, explored the anti-oxidative potentials of xanton, which is abundantly contained in mangosteen pericap. They showed that supplementation of xanton is dose dependently protective against high cholesterolinduced initiation of atherosclerosis as measured by immunohistochemistry of ICAM-1. It is encouraging to have the potential anti-oxidative property of mangosteen pericap as it is abundantly available in the country. However, at least two critical points should be seriously considered if this finding is to be further investigated for clinical significance. First, it is the mangosteen, not the pericap that is consumed by human, thus it will be impossible to perform diet-based epidemiological study to examine the effect of mangosteen pericap on the prevalence of 
atherosclerotic diseases as have been repeatedly shown in Japanese and Chinese population that regularly drink green tea. Second, extracting xanton from the pericap for interventional study would be similar to repeating the failure of previous antioxidants studies where extracting one sole active components from the natural source is thought to disrupt the interaction with other antioxidants and nutrients that resulted in the lost of protective effects.

Only after these two problems can be intelligently solved, the potential therapeutic effect of mangosteen pericap can be seriously tested in a more clinical and causal studies or it may end-up as other antioxidant studies that repeatedly fail to find clinical use

\section{References}

1. Hendarto, Rochman S, Sargowo D. Mangosteen Pericarp Inhibits Nuclear Factor $\kappa \mathrm{B}(\mathrm{NF}-\kappa \mathrm{B})$ Activation and Reduces Expression of ICAM-1 in High Cholesterol diet rat. J Kardiol Indones. 2013;34:23-32

2. Reddy KS. Diet and Cardiovascular Disease. In: Yusuf S, Cairn JA, Fallen EL, Gersh BJ, eds. Evidence-based Cardiology, $3^{\text {rd }}$ ed. Singapore 2010: 111-124

3. Jialal I, Devaraj S. Antioxidants and Atherosclerosis: Don't Throw Out the Baby With the bath water. Circulation. 2003;107:926928

4. Diaz nm, Frei b, Vita ja, Keaney jf. Antioxidants and atherosclerotic heart disease. N eng J Med. 1997;107:410-416 